\title{
PROPOSTA PARA AVALIAR A GESTÃO DA EDUCAÇÃO A DISTÂNCIA DE UMA INSTITUIÇÃO DE ENSINO SUPERIOR A PARTIR DO BALANCED SCORECARD \\ (BSC)
}

\author{
GERSON RIZZATTI JUNIOR \\ ADEMAR DUTRA
}

\section{Resumo}

$\mathrm{O}$ artigo tem por finalidade apresentar uma proposta para avaliar a gestão da educação a distância de uma Instituição de Ensino Superior da região da grande Florianópolis a partir do balanced scorecard (BSC). No que se refere aos procedimentos metodológicos, à pesquisa, se caracteriza por sua abordagem predominantemente qualitativa. Quanto aos meios, se caracteriza por ser um estudo de caso e bibliográfica, e, com relação aos fins, por ser exploratória. A técnica utilizada para a coleta de dados foi a análise documental. Como resultados esta pesquisa apresenta: quatro perspectivas, sociedade, clientes, processos internos e aprendizagem e crescimento, um conjunto de objetivos estratégicos e indicadores para cada uma das perspectivas, e o alinhamento da missão, visão, diretrizes estratégicas, com os objetivos estratégicos e respectivos indicadores propostos.

Palavras-chave: Balanced Scorecard; Educação a Distância; Instituição de Ensino Superior. 


\section{INTRODUÇÃO}

Os grandes desafios enfrentados pelo ensino superior brasileiro exigem respostas imediatas e eficazes. A procura por ampliar o acesso à educação, aumentar a qualidade e produtividade do ensino, pesquisa e extensão, formar adequadamente e manter atualizados os docentes são propostas que só poderão ser concretizadas, caso os métodos tradicionais do sistema educacional sejam reformulados. Evidencia-se a necessidade de se buscar alternativas. Dentre elas, destaca-se a educação à distância (EAD), como um meio flexível e eficaz de enfrentar tais desafios.

A educação a distância vem ocupando a cada ano, um espaço cada vez maior dentro das instituições de ensino superior (IES). Esta modalidade de educação, assim como a presencial, no Brasil, precisa ser gerenciada de forma adequada, pois reflete na qualidade do sistema educacional. Na intenção de se melhorar o gerenciamento, destaca-se a relevância da avaliação da gestão da educação a distância das IES.

Na busca de melhores resultados, os gestores das instituições de ensino superior têm procurado instrumentos de gestão para melhorar continuamente a desempenho institucional. Neste ínterim, o balanced scorecard, devido ao sucesso alcançado junto ao ambiente corporativo, tem se mostrado um instrumento hábil a produzir bons resultados em IES.

Desta forma, este estudo tem como finalidade apresentar uma proposta para avaliar a gestão da educação a distância numa Instituição de Ensino Superior da região da grande Florianópolis a partir do BSC, demonstrando a sua utilidade como ferramenta para conduzir a instituição na efetivação da sua visão, missão e diretrizes estratégicas.

\section{BALANCED SCORECARD}

O balanced scorecard (BSC) é um modelo de medição de desempenho desenvolvido por Kaplan e Norton (2001) após constatações de que os sistemas de controle tradicionais estavam limitados a medidas financeiras e contábeis e que não atendiam as necessidades gerenciais. Esta metodologia desde que foi desenvolvida evoluiu para tornar-se o novo referencial de avaliação das organizações.

Conforme Kaplan e Norton (1997) o BSC é utilizado no intuito de esclarecer e traduzir a visão e a estratégia; comunicar e associar objetivos e medidas estratégicas; planejar, estabelecer metas e alinhar iniciativas estratégicas; e melhorar o feedback e o aprendizado estratégico.

De acordo Kaplan e Norton (1997) o BSC deve traduzir a missão e a estratégia de uma unidade de negócios em objetivos e medidas tangíveis. Tais medidas expressam o equilíbrio entre indicadores externos voltados para acionistas e clientes, e as medidas internas dos processos críticos de negócios, aprendizado e crescimento.

O processo de construção do BSC segundo Kaplan e Norton (1997) ocorre em quatro etapas. Cada etapa é desmembrada em fases visando facilitar a sua aplicação. No quadro abaixo seguem todas as etapas e fases propostas por Kaplan e Norton (1997) para a construção do BSC:

\begin{tabular}{|c|c|}
\hline Etapa & Fase \\
\hline $\begin{array}{l}\text { 1) Definição da arquitetura de } \\
\text { indicadores }\end{array}$ & $\begin{array}{l}\text { Fase } 1 \text { - Selecionar a unidade organizacional adequada } \\
\text { Fase } 2 \text { - Identificar as relações entre a unidade de negócios e a corporação }\end{array}$ \\
\hline $\begin{array}{l}\text { 2) } \mathrm{O} \text { consenso em função dos } \\
\text { objetivos estratégicos }\end{array}$ & $\begin{array}{l}\text { Fase } 3 \text { - Realização da primeira série de entrevistas. } \\
\text { Fase } 4 \text { - Sessão de síntese. } \\
\text { Fase } 5 \text { - Workshop executivo (primeira sessão) }\end{array}$ \\
\hline 3) Escolha e elaboração dos & Fase 6 - Reuniões dos subgrupos. \\
\hline
\end{tabular}




\begin{tabular}{|l|l|l|}
\hline indicadores & Fase 7 - Workshop executivo (segunda sessão) \\
\hline $\begin{array}{l}\text { 4) Elaboração do plano de } \\
\text { implementação }\end{array}$ & $\begin{array}{l}\text { Fase 8 - Desenvolver o plano de implementação. } \\
\text { Fase 9 - Workshop executivo (terceira sessão) } \\
\text { Fase 10 - Finalizar o plano de implementação. }\end{array}$ \\
\hline
\end{tabular}

Quadro 1: Etapas e fases do processo de construção do BSC

Fonte: Adaptado de Kaplan e Norton (1997)

Das etapas e fases acima mencionadas destacam Olve et al (2001) os seguintes pontos: definição das perspectivas, definição dos objetivos estratégicos, desenvolvimento das relações de causa-efeito, elaboração dos indicadores, fixação dos valores para os objetivos e especificação das ações estratégicas.

A utilização do BSC permite aos gestores analisar, através de relações causa-efeito, a forma como cada objetivo pode fazer parte da cadeia de eventos e contribuir para os objetivos globais da organização (NIVEN, 2005).

Para facilitar a visualização das relações causa-efeito, Kaplan e Norton (2001) sugerem a elaboração de um mapa estratégico. O mapa permite visualizar a relações entre os objetivos estratégicos e as perspectivas (NIVEN, 2005).

O BSC na opinião de Kaplan e Norton (1997) pode ser implementado apenas numa unidade da organização, num departamento, numa área funcional ou na organização como um todo. No entanto, salientam os autores que é fundamental começar por uma unidade ou departamento, e depois aplicá-lo em toda a organização. É necessário, conforme Campos (1998), o alinhamento dos objetivos organizacionais com os da unidade de negócio.

\subsection{Perspectivas do balanced scorecard}

O modelo básico de balanced scorecard concebido por Kaplan e Norton (1997) possui quatro perspectivas: financeira, clientes, processos internos e aprendizado e crescimento (Figura 1). Contudo, em decorrência do setor de negócio e da estratégia da organização, podese fazer necessário agregar outras perspectivas ao modelo.

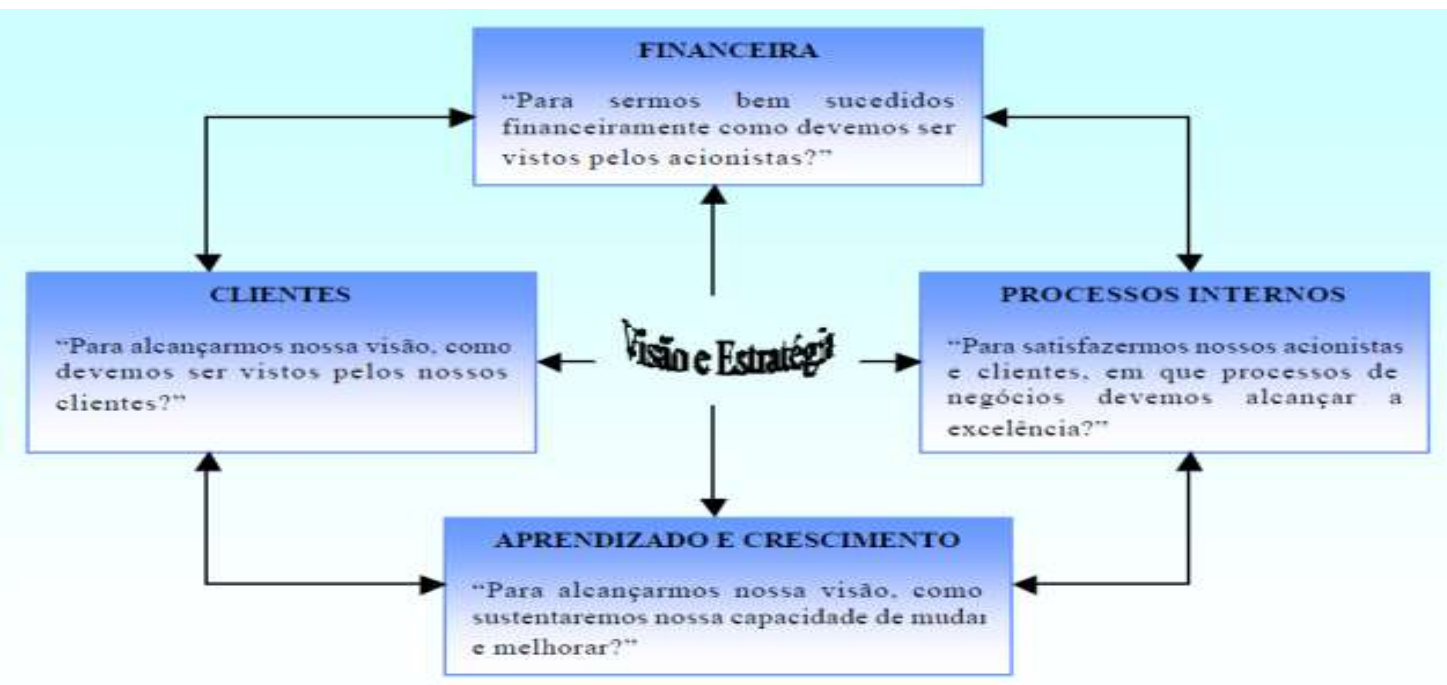

Figura 1: Perspectivas do balanced scorecard Fonte: Adaptado de Kaplan e Norton (1997)

A perspectiva financeira tem por objetivo avaliar se a implementação da estratégia contribuirá para a melhoria dos resultados financeiros da organização. Além disso, esta perspectiva é importante para avaliar as consequências econômicas das ações implementadas. 
Os objetivos da perspectiva financeira servirão de foco para os objetivos e indicadores das demais perspectivas. (KAPLAN; NORTON, 1997).

A perspectiva cliente está direcionada para a identificação de quais clientes e mercados a organização deseja conquistar e manter, além de apresentar propostas de geração de valor aos clientes. São os clientes que irão possibilitar o alcance dos objetivos financeiros da empresa, e, por isso, é fundamental satisfazê-los e retê-los (KAPLAN; NORTON, 1997).

$\mathrm{Na}$ perspectiva processos internos, segundo Kaplan e Norton (1997) procura-se identificar todos os processos críticos que afetam os resultados estabelecidos para as perspectivas clientes e finanças. Recomendam os autores que se defina toda a cadeia de valor para os processos internos, iniciando pelo processo de inovação, identificando as necessidades atuais e futuras dos clientes e desenvolvendo soluções para o atendimento dessas necessidades (KAPLAN; NORTON, 1997).

A perspectiva aprendizado e crescimento proporcionam o alcance dos objetivos traçados para as demais perspectivas. São criadas medidas para avaliar a capacidade dos funcionários, o aperfeiçoamento da tecnologia da informação e dos sistemas, e o alinhamento dos procedimentos e rotinas organizacionais (KAPLAN; NORTON, 1997). Complementam Maholland e Muetz (2002) no tocante a esta perspectiva que as organizações devem ter empregados qualificados para realizar sua missão e estratégia, e, para tanto, conforme os autores é importante a adaptação dos empregados a um contínuo ambiente de mudança.

\subsection{Perspectivas do BSC para instituições de ensino superior sem fins lucrativos}

Por se tratar a organização objeto deste estudo de uma instituição de ensino superior sem fins lucrativos, passa-se na sequência a destacar alguns levantamentos apontados na literatura para a adequação de perspectivas ao modelo básico concebido por Kaplan e Norton (1997). Os próprios autores argumentam que o modelo não é rígido, podendo ser modificado conforme as estratégias ou ramo de atuação da organização. Reforça esta idéia Campos (1998) ao comentar que as organizações não devem se restringir unicamente às quatro perspectivas básicas.

Questiona Pessoa (2000) a existência da perspectiva financeira nas instituições de ensino superior que não visam o lucro, pois o papel desempenhado pelos objetivos financeiros servirá como inibidor, sendo raramente um objetivo básico.

Para Muller (2001) os resultados da gestão de uma instituição de ensino superior não devem ser medidos pelos seus aspectos financeiros, dado que não têm fins lucrativos, mas sim pelo impacto dos seus projetos na sociedade, isto é, a sua contribuição para o desenvolvimento social, econômico e cultural.

O resultado social será o retorno que a sociedade obtém da instituição, a partir do desenvolvimento dos seus programas e projetos, ou seja, a instituição de ensino superior sustentada pelo ensino, pesquisa e extensão eleva o nível intelectual da sociedade, através da produção, sistematização e socialização do conhecimento, fazendo com que as pessoas possam melhorar a qualidade de vida da população (MULLER, 2001).

Muller (2001) entende que os interesses sociais estão incluídos, em parte, na perspectiva dos clientes, no entanto, cria a perspectiva social, pois esta assume uma importância especial nas instituições de ensino superior. Estas instituições terão de se preocupar com a abrangência e repercussão social dos seus projetos.

Se uma instituição de ensino superior apresenta um bom resultado social consequentemente atrai mais alunos, mais projetos e obtém maior reconhecimento da comunidade. Estes fatores proporcionarão mais recursos, dando origem a mais projetos e parcerias e maior reconhecimento do ensino e das atividades de extensão (MULLER, 2001). 


\subsection{Objetivos estratégicos e indicadores}

Os objetivos estratégicos conforme Kaplan e Norton (1997) devem traduzir a estratégia da organização e permitir o estabelecimento de relações causa-efeito entre as várias perspectivas. Este fato é preponderante, pois tem influência sobre o êxito da execução da estratégia.

A determinação dos objetivos estratégicos para cada perspectiva será o ponto de partida para todas as atividades durante a elaboração do BSC. E, para se ter bons indicadores, é necessário que os objetivos em que se baseiam descrevam corretamente a estratégia (PESSOA, 2000).

Os indicadores devem expressar os objetivos estratégicos de forma clara e inequívoca. A sua escolha deve ser feita de modo coerente com a visão, missão e estratégia da organização (KAPLAN; NORTON, 1997). Acrescenta Johnsen (2001) que os indicadores devem permitir a medição dos objetivos estratégicos definidos.

Assinalam Olve et al (2001) que o BSC deve combinar indicadores de resultado com indicadores de desempenho. Esta conjugação é importante, pois, os indicadores de resultado sem os de desempenho não comunicam a forma como os resultados devem ser atingidos, nem mostram antecipadamente se a estratégia está sendo bem sucedida. Por outro lado, os indicadores de desempenho sem os de resultado podem permitir que a unidade de negócio obtenha melhorias operacionais de curto prazo, mas não revelam se as mesmas se traduziram num melhor desempenho financeiro.

\section{EDUCAÇÃO A DISTÂNCIA}

A Educação a Distância (EAD) já tem um longo caminho percorrido. Sua origem remonta a 1728, quando o jornal Gazeta de Boston publicou um anúncio oferecendo cursos por correspondência. $\mathrm{O}$ trajeto que essa modalidade educacional percorreu desde então foi diretamente influenciada pelas tecnologias da comunicação que, a cada inovação, contribuem na redução de distâncias (LANDIM, 1997).

No Brasil a educação a distância teve seu início com o ensino por correspondência, tendo como marco o ano de 1904 (ALVES, 1999). Uma das primeiras experiências universitárias de EAD no Brasil foi iniciada pela Universidade de Brasília em meados de 1970 baseado na iniciativa Britânica, com a Open University (PRETI, 1996).

A educação a distância tem sido um componente valioso do sistema educacional e tem demonstrado ser compensadora em áreas nas quais as instituições de ensino superior têm dificuldades de atender toda a demanda ou mesmo como complemento à educação convencional (KEEGAN, 1996).

A educação a distância tornou-se ao longo dos anos, um conjunto de técnicas e abordagens metodológicas que, com o uso de tecnologias da informação e da comunicação, puderam colaborar para a redução da distância transacional e indução da aproximação afetiva, relacional e comunicacional fundamental à aprendizagem (AZEVEDO, apud JACOBSEN, 2004).

Segundo Aretio (1994) a educação a distância é uma estratégia educativa baseada na aplicação da tecnologia à aprendizagem sem limitação de lugar, tempo, ocupação ou idade dos estudantes. Tal modalidade de ensino implica novas relações para os alunos e para os professores, novas atitudes e novos enfoques metodológicos.

Ramos et al (1989) comenta que a educação a distância é uma alternativa para a educação formal, tendo a vantagem de ser mais dinâmica e voltada para a aprendizagem individualizada, pois permite que a pessoa progrida segundo suas próprias necessidades.

Conforme Roberts (apud JACOBSEN, 2004) a educação a distância foi projetada para 
servir alunos que não têm possibilidades por razões geográficas ou de disponibilidade de tempo, para frequentar cursos presenciais.

Aretio (1994) apresenta as principais particularidades da educação a distância: separação física entre professor e aluno, atividades docentes e discentes assíncronas, uso de tecnologia orientada para a mídia, aprendizagem independente e flexível, comunicação bidirecional, organização de apoio-tutoria, enfoque tecnológico, comunicação massificada e processos industrializados.

A eficácia da educação a distância segundo Preti (1996) encontra-se hoje comprovada e, é importante que se conceba tal modalidade de educação como um sistema que possibilite o atendimento de qualidade, acesso ao ensino, além de se constituir em uma forma de democratização do saber.

Embora se apresente como uma metodologia não-convencional e não-formal, que utiliza os recursos dos modernos meios de comunicação para fazer avançar o processo educativo, a educação a distância deve submeter a utilização dos meios de comunicação à desmassificação, ao desenvolvimento de espírito crítico e à potenciação da capacidade comunicativa, que visam o domínio de outras linguagens. Assim, em EAD torna-se necessário um planejamento cuidadoso do processo de transmissão e de construção do conhecimento (LITWIN, 2001).

$\mathrm{O}$ projeto de $\mathrm{EAD}$, por sua natureza, requer uma gestão diferenciada, isso porque nessa modalidade de ensino, o aluno se encontra distante, o que exige da instituição um atendimento pedagógico, acadêmico e administrativo diferente daquele prestado a alunos de cursos na moda idade presencial (UNISUL VIRTUAL, 2004a).

Conforme dados da Unisul Virtual (2004a) o perfeito funcionamento de um curso na modalidade a distância exige planejamento, desenvolvimento e execução de diferentes atividades, por isso constitui-se num trabalho de equipe, além do que, os conhecimentos requeridos são multidisciplinares, exigindo a participação de:

- docentes especializados nas áreas abrangidas pelo curso;

- profissionais que gerenciem os recursos e processos do curso;

- técnicos especializados no processo de produção dos materiais didáticos;

- pessoal de apoio e suporte (monitores, engenheiros e programadores);

- terceiros (fornecedores de materiais e de serviços).

Mason (2001) relaciona os elementos-chave para instituições que trabalham com Educação Superior a Distância: currículo; preparação dos cursos; estrutura de suporte aos alunos; avaliação dos alunos e emissão de certificado; e questões administrativas.

Conforme Saraiva (1996) a educação a distância exige atendimento pedagógico superador da distância, que promova a essencial relação professor-aluno, por meios e estratégias institucionalmente garantidas.

Enfatiza Martins (1991) que são pontos fundamentais para o sucesso da educação a distância, a utilização racional de audiovisuais, a confecção do material didático e a elaboração de textos que utilizem linguagem clara e sensível, de modo que o conteúdo se torne atraente e interessante ao aluno.

\section{PROCEDIMENTOS METODOLÓGICOS}

Em função da problemática estudada, a natureza da pesquisa configura-se predominantemente como qualitativa. Tal enfoque ocupa um reconhecido lugar entre as várias possibilidades de se estudar fenômenos que envolvam seres humanos e suas intrincadas relações sociais estabelecidas em diversos ambientes (GODOY, 1995).

Nesta pesquisa utilizou-se o critério metodológico proposto por Vergara (1997). Esta estabelece que a pesquisa pode ser realizada de acordo com os fins e meios necessários. 
Quanto aos fins, a pesquisa se caracteriza por ser exploratória, pois proporcionou ao pesquisador maiores informações a respeito do assunto investigado, tornando possível à realização de futuras pesquisas (GIL, 1998).

Quanto aos meios, esta pesquisa se caracteriza por ser bibliográfica e um estudo de caso. Bibliográfica, tendo em vista que foi utilizado neste estudo todo material publicado e acessível ao pesquisador sobre balanced scorecard e educação à distância. E, estudo de caso por estar fundada na análise intensiva de uma unidade de uma instituição, conforme preceitua Bruyne (1977). No caso em questão, estudou-se a unidade de uma Instituição de Ensino Superior da região da grande Florianópolis que oferece cursos de pós graduação e graduação a distância.

Nesta pesquisa foram utilizados dados provenientes de fontes secundárias. Inicialmente buscou-se para realização da pesquisa, na literatura específica, subsídio para instruir o pesquisador sobre o tema, e, ainda, delinear os limites e as contribuições do estudo realizado. Posteriormente, partiu-se para análise dos documentos produzidos pela instituição sobre os seus cursos de educação a distância.

A análise documental se ateve aos seguintes documentos obtidos junto a instituição: históricos, avaliações das atividades pedagógicas e administrativas, relatórios, entre outros que foram produzidos e que estão arquivados na instituição.

Considerando limitações que pesquisas empíricas tendem a apresentar, citam-se na sequência algumas encontradas neste estudo:

a) restrição quanto a subjetividade do pesquisador no tocante as perspectivas, objetivos estratégicos e indicadores propostos para avaliação da gestão da educação a distância;

b) esta pesquisa restringe-se a um estudo de caso, desta forma seus resultados não podem ser aplicados a outras instituições;

c) os indicadores e objetivos estratégicos não foram validados; e

d) não foram estabelecidas metas para cada um dos indicadores propostos.

\section{PROPOSTA PARA A INSTITUIÇÃO DE ENSINO SUPERIOR}

Tendo por base a revisão bibliográfica efetuada e os documentos levantados na instituição objeto deste estudo é apresentado neste item uma proposta para se avaliar a gestão da educação a distância de uma IES localizada na região da grande Florianópolis a partir do BSC. A proposta se restringiu a elaboração de perspectivas, objetivos estratégicos e indicadores.

Para que o objetivo definido pelo pesquisador fosse alcançado foram concebidas quatro etapas que podem ser evidenciadas na sequência deste estudo:

Primeira etapa: definição da unidade organizacional e de sua visão e missão.

A unidade estratégica estudada é a responsável na instituição pelos cursos de EAD. A IES em análise está credenciada e habilitada pelo MEC a oferecer cursos de educação superior a distância para todo o Brasil.

A produção acadêmica da educação a distância da IES desde o seu surgimento em 1998 até o momento, é de mais de 200 disciplinas, o que inclui a distribuição de 97.000 exemplares de apostilas para os alunos. A educação a distância da IES conta hoje com mais de 6.000 alunos distribuídos por todo o Brasil e, ainda, em alguns países como Estados Unidos, Moçambique, São Tomé e Príncipe.

Para proporcionar cursos de EAD, fora desenvolvido um Ambiente Virtual de Aprendizagem, sistema este elaborado e desenvolvido com recursos de informática e da tecnologia para facilitar e apoiar o processo ensino-aprendizagem entre tutores, alunos e monitores. 
O modelo pedagógico adotado pela instituição garante flexibilidade aos alunos, permitindo a escolha dos horários e locais de estudo, com o acompanhamento de professores, além de atendimento permanente via internet. $\mathrm{O}$ único encontro presencial é na época das avaliações, no final de cada módulo.

Atualmente a IES oferece 13 cursos de graduação tecnológica, 8 de graduação (bacharelado e licenciatura) e 11 de pós-graduação em nível de especialização, com diploma válido em todo o país.

A IES realiza convênios com outras instituições de ensino superior, com os setores público e privado e com organizações não-governamentais oferecendo cursos de educação a distância. Em 2008, a IES assinou um convênio com as seguintes organizações: Agência Nacional de Aviação Civil, Escola Superior de Guerra e Ministério da Defesa, beneficiando todos os servidores ativos e inativos destas, bem como seus respectivos familiares.

Diante das peculiaridades da educação a distância, apresenta-se na sequência a estrutura organizacional da Instituição de Ensino Superior em análise (Figura 2):

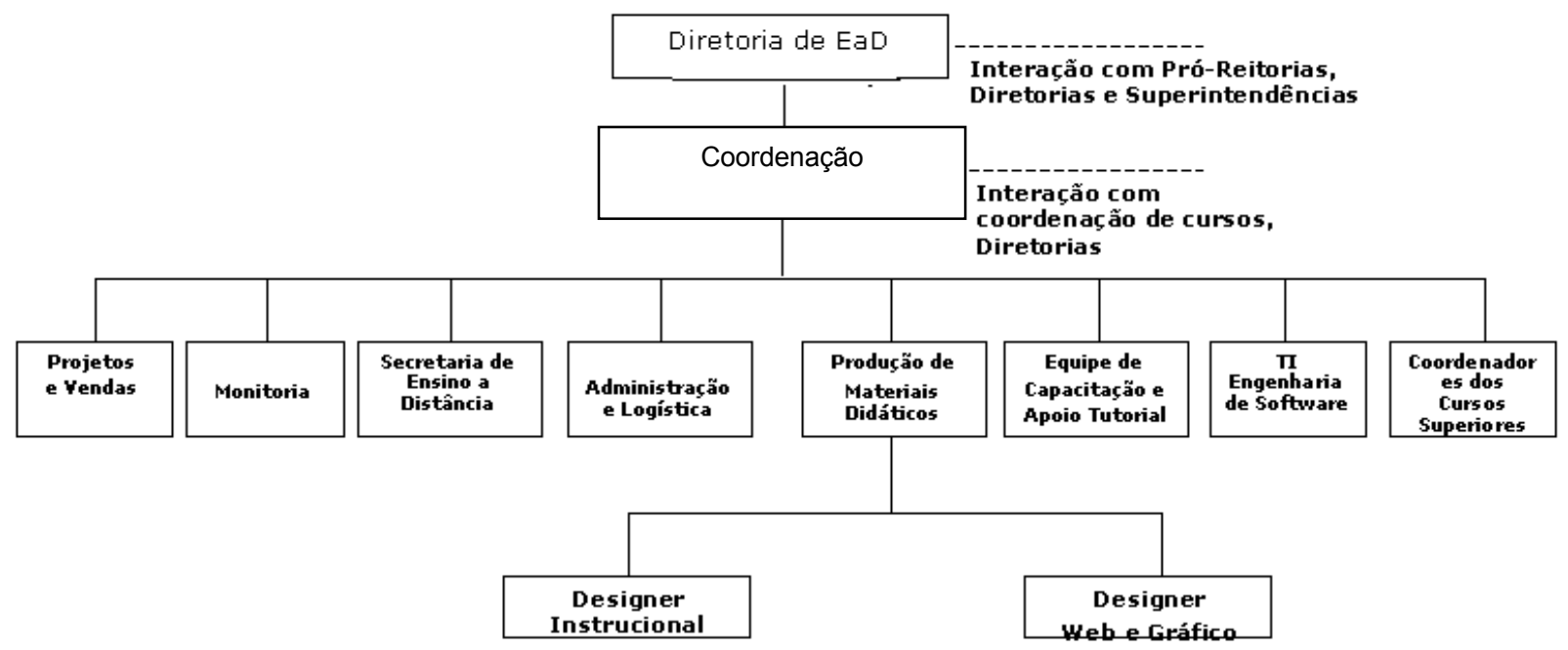

Figura 2: Estrutura organizacional da IES

Fonte: Dados da pesquisa

O sistema tutorial da unidade institucional é responsável pelo gerenciamento, pelo suporte técnico e pedagógico dos estudantes durante a execução dos cursos. Ele é composto por diversos agentes, formando uma equipe que atua e desenvolve um trabalho de integração e coordenação do processo em sua totalidade, são eles: coordenação da unidade, coordenação do curso, equipe de capacitação e apoio pedagógico à tutoria, professores autores e tutores e monitores.

A missão, visão e as diretrizes estratégicas da instituição foram definidas no seu planejamento estratégico. Tais aspectos são importantes para se avaliar a gestão da educação a distância da unidade em estudo.

A elaboração do atual planejamento estratégico da instituição contou com a participação de seus principais gestores. No ano de 2005 ocorreu um encontro com mais de 200 gestores buscando integrar, comunicar e comprometer os mesmos com os resultados obtidos na construção do planejamento estratégico elaborado de forma participativa, bem como validar direcionadores e objetivos estratégicos para toda a instituição (FERREIRA, 2005). 
No mesmo encontro buscou-se revisar a missão, a visão e os valores da instituição que haviam sido definidos no planejamento estratégico anterior. Finalizado o encontro, estava definida à missão, visão e aos valores para toda a instituição (FERREIRA, 2005).

Este estudo foi desenvolvido junto a unidade da IES, que atua exclusivamente na educação a distância. Assim, passa-se, na sequência, a declaração da sua missão e visão contidas no planejamento estratégico.

A missão da unidade de EaD da IES é a seguinte: educação e gestão inovadoras e criativas no processo do ensino, da pesquisa e da extensão, para formar integralmente, ao longo da vida, cidadãos capazes de contribuir na construção de uma sociedade humanizada, em permanente sintonia com os avanços da ciência e da tecnologia. Já a visão foi definida nos seguintes termos: ser reconhecida como a melhor instituição de educação a distância do Brasil.

No planejamento estratégico da IES fora fixado também os direcionadores estratégicos que serão destacados na sequência deste estudo. Estes foram concebidos durante o encontro de gestores, e posteriormente encaminhados para reitoria com a finalidade de validação (FERREIRA, 2005).

\section{Segunda etapa: definição das perspectivas do BSC.}

Foram definidas as seguintes perspectivas para o BSC da IES: sociedade, clientes, processos internos e aprendizagem e crescimento. A perspectiva sociedade foi proposta para a instituição de ensino superior tendo em vista que a mesma visa fomentar o desenvolvimento social e econômico através do ensino, pesquisa e extensão. A IES objetiva ser reconhecida como a melhor instituição de educação a distância do Brasil.

A perspectiva cliente foi mantida conforme a proposta metodológica concebida por Kaplan e Norton (1997). Cabe salientar que os principais clientes das instituições de ensino superior são os alunos, dado ser com eles que ela mantém relações diretas. Os alunos são os principais clientes do serviço educativo; sem eles não existirá a transmissão de conhecimento.

A perspectiva processos internos também foi preservada. Tais processos estão centrados nos processos acadêmicos e administrativos que são fundamentais para aperfeiçoar o ensino, pesquisa e extensão da educação a distância da IES.

Por não possuir a instituição de ensino superior em estudo fins lucrativos, optou-se por não adotar a perspectiva financeira, pois ela representa uma limitação e não uma prioridade. Assim, no que tange ao aspecto financeiro, a instituição visa apenas captar e gerir recursos necessários a sua manutenção e expansão, sendo desta forma inserido pelo pesquisador dentro da perspectiva processos internos como um objetivo estratégico.

Por fim, a perspectiva aprendizado e crescimento mostra-se fundamental para instituições de ensino superior, pois estas precisam investir permanentemente na qualificação do seu corpo docente e funcionários para melhorar a prestação dos seus serviços e a qualidade dos processos de pesquisa, ensino e extensão.

Terceira etapa: identificação dos objetivos estratégicos para cada perspectiva a partir das diretrizes estratégicas.

Definida as perspectivas para compor o BSC, buscou-se resgatar no planejamento as diretrizes estratégicas concebidas para toda a instituição com o intuito de definir os objetivos estratégicos para a unidade institucional estudada. No quadro 2, pode-se evidenciar o alinhamento entre a perspectiva e os objetivos que foram definidos para cada uma das diretrizes.

\begin{tabular}{|l|l|l|}
\hline Diretrizes Estratégicas & \multicolumn{1}{|c|}{ Objetivos estratégicos } & \multicolumn{1}{|c|}{ Perspectiva } \\
\hline $\begin{array}{l}\text { Educação Inovadora, } \\
\text { criativa e de qualidade }\end{array}$ & $\begin{array}{l}\bullet \text { Ser reconhecida pelos alunos e sociedade como a melhor IES em EAD } \\
\text { do Brasil }\end{array}$ & Sociedade \\
\cline { 2 - 3 } & $\begin{array}{l}\bullet \text { Ser reconhecida na sua rede de relacionamento e pela sociedade por } \\
\text { sua contribuição }\end{array}$ & Sociedade \\
\hline
\end{tabular}




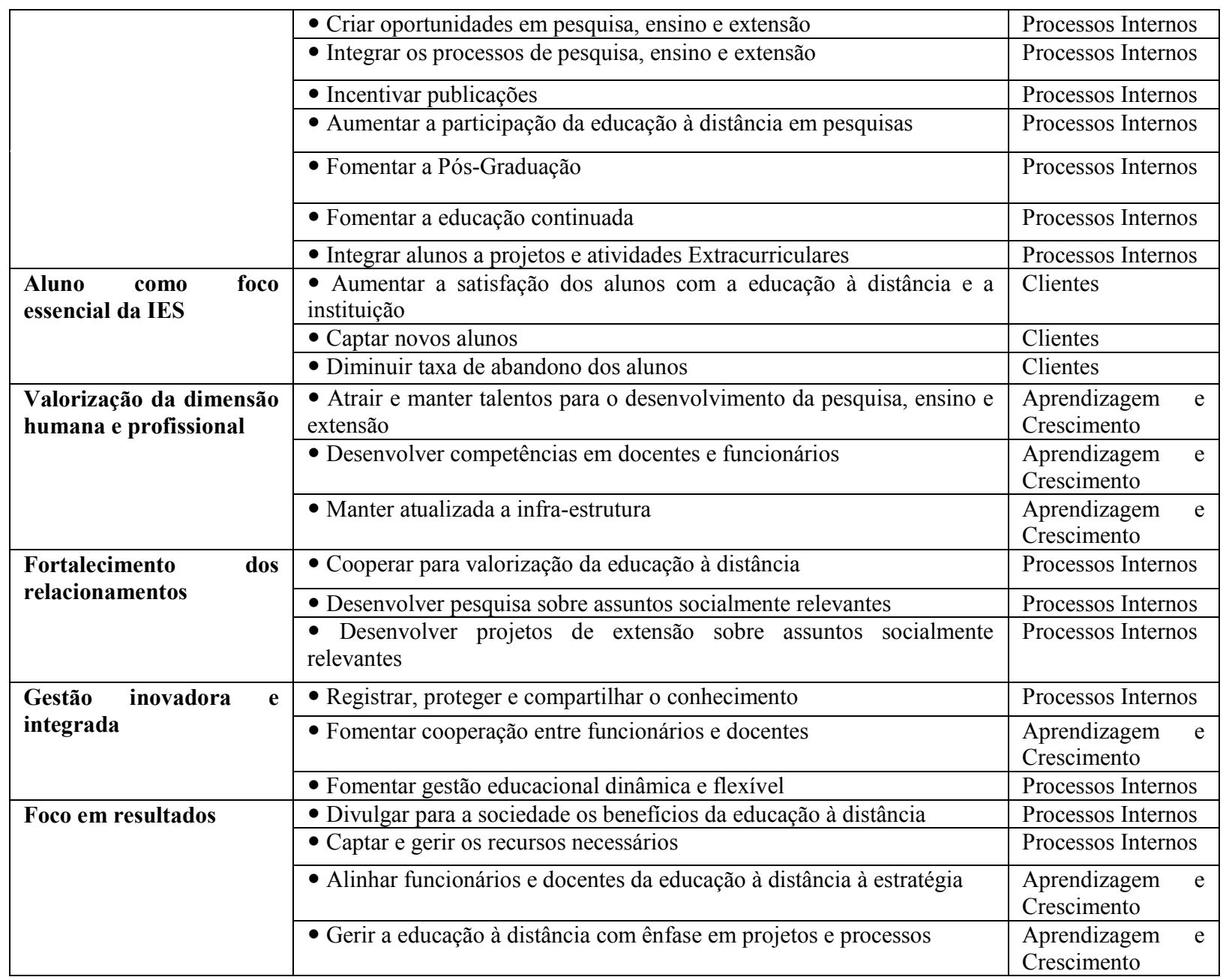

Quadro 2: Definição de objetivos estratégicos para cada diretriz estratégica

Fonte: Elaborado pelo autor

O retorno social para a IES é o elemento central a ser avaliado pelo BSC, e não os resultados financeiros. Esta alteração origina modificações na definição das relações, ou seja, a base das relações começa na perspectiva aprendizagem e crescimento e no topo das relações estará à perspectiva sociedade.

Tendo por base as considerações anteriores e os objetivos estratégicos definidos para cada perspectiva, apresenta-se na figura 3 o mapa estratégico da unidade institucional: 


\section{Instituição de Ensino Superior}

Ser reconhecida como a melhor instituiçâo de ensino a distància do Brasil.

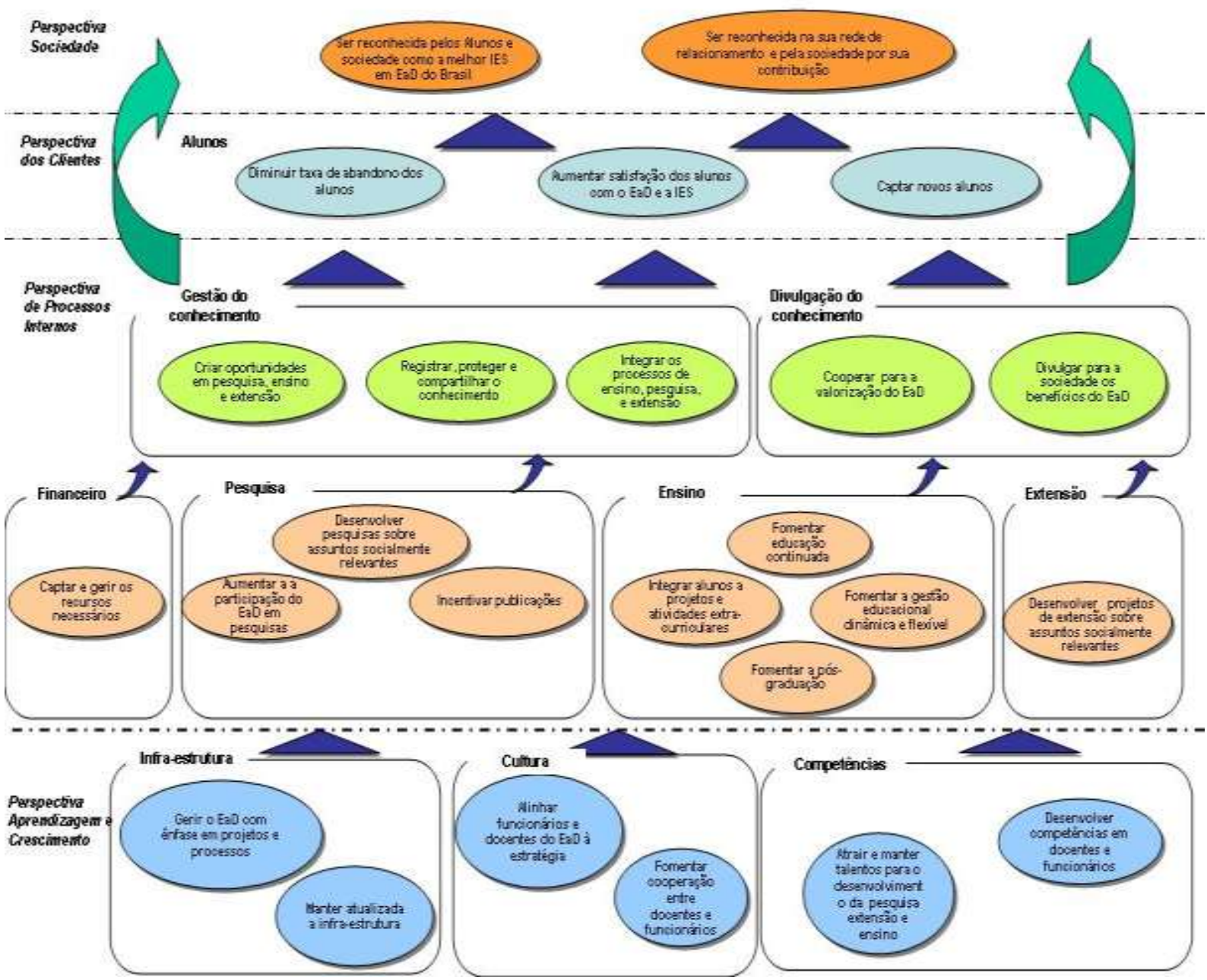

Figura 3: Mapa estratégico da IES

Fonte: Elaborado pelo autor

A cadeia de relações ilustra as ligações entre os diversos objetivos estratégicos estabelecidos para cada uma das perspectivas. O detalhamento dessas relações é fundamental para que se possa verificar a lógica do conjunto.

Observando o mapa estratégico pode-se verificar o seguinte fluxo de relações de causa-efeito: o investimento no capital humano e em infra-estrutura (perspectiva de aprendizagem e crescimento) implica na melhoria e consolidação dos processos de ensino, pesquisa e extensão (perspectiva dos processos internos), que por sua vez afeta no aumento da satisfação dos acadêmicos e ajuda a captar novos alunos (perspectiva do cliente). Tudo isso contribui para que a instituição possa ser reconhecida como a melhor instituição em EAD do país (perspectiva sociedade).

Quarta etapa: eleger os indicadores para cada objetivo estratégico.

No quadro 3 segue os indicadores levantados para os objetivos estratégicos da perspectiva sociedade:

\begin{tabular}{|c|c|}
\hline \multicolumn{2}{|c|}{ PERSPECTIVA SOCIEDADE } \\
\hline Objetivo estratégico & Indicador \\
\hline Ser reconhecida pelos alunos e sociedade como a melhor & $\bullet$ Conceito do curso nas avaliações externas \\
\hline
\end{tabular}




\begin{tabular}{|l|l|}
\hline Instituição de Ensino Superior (IES) em EAD do Brasil & $\begin{array}{l}\bullet \text { Demanda pelos cursos } \\
\bullet \text { Grau de satisfação do mercado com os egressos }\end{array}$ \\
\hline $\begin{array}{l}\text { Ser reconhecida na sua rede de relacionamento e pela } \\
\text { sociedade por sua contribuição }\end{array}$ & $\begin{array}{l}\bullet \text { Índice de satisfação com base na pesquisa de opinião pública } \\
\text { e com os parceiros da rede de relacionamento } \\
\bullet \text { Índice de empregabilidade dos atuais e ex-alunos } \\
\bullet \text { Número de convênios com empresas ou instituições públicas }\end{array}$ \\
\hline
\end{tabular}

Quadro 3: Indicadores dos objetivos estratégicos da perspectiva sociedade

Fonte: Elaborado pelo autor

Como pode-se observar no quadro 3, para cada um dos objetivos foram levantados três indicadores, julgados adequados pelo pesquisador para medir o alcance dos objetivos propostos.

No quadro 4 segue os indicadores para os objetivos da perspectiva clientes:

\begin{tabular}{|l|l|}
\hline \multicolumn{1}{|c|}{ PERSPECTIVA CLIENTES } \\
\hline \multicolumn{1}{|c|}{ Objetivo estratégico } & \multicolumn{1}{c|}{ Indicador } \\
\hline $\begin{array}{l}\text { Aumentar a satisfação dos alunos com da educação a a } \\
\text { distância e a instituição }\end{array}$ & $\begin{array}{l}\bullet \text { Número de reclamações } \\
\bullet \text { Índice da satisfação }\end{array}$ \\
\hline Captar novos alunos & $\bullet$ Número de novos alunos \\
\hline Diminuir taxa de abandono dos alunos & $\bullet$ Taxa de abandono por curso \\
\hline
\end{tabular}

Quadro 4: Indicadores dos objetivos estratégicos da perspectiva clientes

Fonte: Elaborado pelo autor

Cada um dos objetivos levantados pelo pesquisador para compor a perspectiva clientes possui um indicador que permite medi-lo.

Abaixo, no quadro 5, seguem os indicadores dos objetivos estratégicos da perspectiva aprendizagem e crescimento:

\begin{tabular}{|c|c|}
\hline \multicolumn{2}{|c|}{ PERSPECTIVA PROCESSOS INTERNOS } \\
\hline Objetivo estratégico & Indicador \\
\hline Criar oportunidades em pesquisa, ensino e extensão & $\begin{array}{l}\text { - Tempo de desenvolvimento de novos cursos } \\
\text { - Número de atividades de extensão aprovadas } \\
\text { - Número de cursos de educação a distância da IES } \\
\text { - Quantidade de projetos de pesquisa }\end{array}$ \\
\hline Registrar, proteger e compartilhar o conhecimento & $\begin{array}{l}\text { - Número de artigos e trabalhos de conclusão de curso disponíveis } \\
\text { em meio magnético } \\
\text { - Quantidade de eventos de disseminação do conhecimento }\end{array}$ \\
\hline Integrar os processos de pesquisa, ensino e extensão & $\begin{array}{l}\text { - Número de professores que atuam simultaneamente na pesquisa, } \\
\text { ensino e extensão } \\
\text { - Número de alunos que participam tanto dos projetos de pesquisa } \\
\text { quanto de extensão }\end{array}$ \\
\hline Cooperar para valorização da educação a distância & $\begin{array}{l}\text { - Número de eventos realizados para consolidar a educação a } \\
\text { distância }\end{array}$ \\
\hline $\begin{array}{l}\text { Divulgar para a sociedade os benefícios da educação a } \\
\text { distância }\end{array}$ & $\begin{array}{l}\text { - Número de entrevistas e matérias publicadas na mídia impressa } \\
\text { e falada sobre a educação a distância da IES }\end{array}$ \\
\hline Captar e gerir os recursos necessários & $\begin{array}{l}\text { - Número de cursos lançados por semestre } \\
\text { - Valores investidos em pesquisa } \\
\text { - Valores investidos em ensino } \\
\text { - Percentual de inadimplência no recebimento das mensalidades }\end{array}$ \\
\hline Incentivar publicações & $\begin{array}{l}\text { - Número de trabalhos publicados } \\
\text { - Número de canais de publicação oferecidos pela instituição }\end{array}$ \\
\hline $\begin{array}{l}\text { Aumentar a participação da educação a distância em } \\
\text { pesquisas }\end{array}$ & $\begin{array}{l}\text { - Tempo dos professores e alunos em pesquisas } \\
\text { - Número de alunos e professores em grupos de pesquisa }\end{array}$ \\
\hline $\begin{array}{l}\text { Desenvolver pesquisa sobre assuntos socialmente } \\
\text { relevantes }\end{array}$ & $\begin{array}{l}\text { - Grau de relevância da pesquisa } \\
\text { - Número de pessoas beneficiadas }\end{array}$ \\
\hline Fomentar a pós-graduação & $\begin{array}{l}\text { - Conceito dos cursos de pós-graduação na avaliação externa } \\
\text { - Número de alunos matriculados na pós-graduação } \\
\text { - Número de cursos de pós-graduação }\end{array}$ \\
\hline Fomentar a educação continuada & - Número de alunos que voltaram a estudar na IES \\
\hline Integrar alunos a projetos e atividades extracurriculares & $\begin{array}{l}\text { - Número de alunos envolvidos em projetos e atividades } \\
\text { Extracurriculares }\end{array}$ \\
\hline
\end{tabular}




\begin{tabular}{|l|l|}
\hline Fomentar gestão educacional dinâmica e flexível & $\bullet$ Grau de flexibilidade e dinâmica da gestão educacional \\
\hline $\begin{array}{l}\text { Desenvolver projetos de extensão sobre assuntos } \\
\text { socialmente relevantes }\end{array}$ & $\begin{array}{l}\bullet \text { Grau de relevância do projeto } \\
\bullet \text { Número de pessoas beneficiadas }\end{array}$ \\
\hline
\end{tabular}

Quadro 5: Indicadores dos objetivos estratégicos da perspectiva processos internos

Fonte: Elaborado pelo autor

Diante da análise dos objetivos estratégico da perspectiva processos internos constatase que alguns objetivos receberam mais de um indicador para que pudessem ser avaliados adequadamente.

No quadro 6, pode-se observar os indicadores dos objetivos estratégicos da perspectiva aprendizagem e crescimento:

\begin{tabular}{|c|c|}
\hline \multicolumn{2}{|c|}{ PERSPECTIVA APRENDIZAGEM E CRESCIMENTO } \\
\hline Objetivo estratégico & Indicador \\
\hline $\begin{array}{l}\text { Gerir a educação a distância com ênfase em projetos e } \\
\text { processos }\end{array}$ & - Nível de adequação do modelo de gestão com o objetivo \\
\hline $\begin{array}{l}\text { Manter atualizada a infra-estrutura para pesquisa e } \\
\text { ensino }\end{array}$ & - Tempo de atualização da infra-estrutura de pesquisa e de ensino \\
\hline Fomentar cooperação entre funcionários e docentes & $\begin{array}{l}\text { - Grau de cooperação evidenciado em estudo de clima } \\
\text { organizacional entre docentes e funcionários }\end{array}$ \\
\hline $\begin{array}{l}\begin{array}{l}\text { Alinhar funcionários } \\
\text { distância à estratégia }\end{array} \\
\end{array}$ & $\begin{array}{l}\text { - Grau de adesão evidenciado em estudo de clima organizacional } \\
\text { entre professores e funcionários }\end{array}$ \\
\hline $\begin{array}{l}\text { Atrair e manter talentos para o desenvolvimento da } \\
\text { pesquisa, ensino e extensão }\end{array}$ & $\begin{array}{l}\text { - Índice de atração e retenção de talentos } \\
\text { - Grau de satisfação dos funcionários e docentes talentosos com a } \\
\text { educação a distância da IES }\end{array}$ \\
\hline Desenvolver competências em docentes e funcionários & $\begin{array}{l}\text { - Número de docentes e funcionários que participaram do } \\
\text { processo de desenvolvimento de competências }\end{array}$ \\
\hline
\end{tabular}

Quadro 6: Indicadores dos objetivos estratégicos da perspectiva aprendizagem e crescimento

Fonte: Elaborado pelo autor

Foram levantados seis objetivos estratégicos para a perspectiva aprendizagem e crescimento. Para cada um deles foram concebidos indicadores que possibilitam avaliar como os objetivos poderão ser alcançados.

Os indicadores elaborados permitirão evidenciar o alcance dos objetivos estratégicos propostos a partir das diretrizes estratégicas definidas para a Instituição de Ensino Superior.

$\mathrm{O}$ artigo se restringe a definição dos indicadores para compor cada um dos objetivos estratégicos das perspectivas do BSC. O estabelecimento de metas e ações demandaria uma outra abordagem, o que não foi objeto deste estudo.

\section{CONCLUSÃO}

Este artigo apresentou uma proposta de avaliação da gestão da educação a distância de uma Instituição de Ensino Superior a partir do balanced scorecard.

A metodologia desenvolvida por Kaplan e Norton (1997) para o balanced scorecard centra-se na análise de quatro perspectivas: finanças, clientes, processos internos e aprendizagem e crescimento. No entanto, a investigação efetuada permitiu verificar que o número de perspectivas pode variar dependendo de várias particularidades como o ramo de atuação e estratégia da organização.

A constatação de que o modelo é utilizado no ambiente corporativo com grande sucesso, suscitou dúvida sobre a sua aplicação em instituições de ensino sem fins lucrativos. Verificou-se então a necessidade de serem efetuadas algumas alterações no modelo concebido por Kaplan e Norton (1997), que vão desde a criação de uma nova perspectiva, a sociedade, diante do propósito estabelecido na visão e missão da instituição e a retirada da perspectiva financeira, que passou a ser apenas um objetivo dentro da perspectiva processos internos, haja 
vista a preocupação social das organizações sem fins lucrativos, como a instituição de ensino superior objeto deste estudo. Assim, ficaram definidas as seguintes perspectivas: sociedade, clientes, processos internos e aprendizagem e crescimento.

A proposta concebida pelo pesquisador visa fornecer a instituição uma ferramenta capaz de avaliar o alcance de suas estratégias. A sistematização de perspectivas, objetivos estratégicos e indicadores é um importante diferencial, pois pode melhor os aspectos internos e contribuir para a oferta de serviços de qualidade aos alunos e a sociedade.

Outra contribuição deste estudo foi a elaboração a partir das diretrizes estratégicas definidas no planejamento estratégico da Instituição de Ensino Superior, dos objetivos estratégicos e seus respectivos indicadores para compor cada uma das perspectivas do BSC da IES.

No estudo realizou-se o alinhamento da missão, visão e diretrizes estratégicas da Instituição de Ensino Superior aos objetivos estratégicos e indicadores concebidos pelo pesquisador, mostrando a todo momento a relevância da questão social, diante do reconhecimento que a instituição busca frente a sociedade.

Por fim, cabe mencionar que os indicadores levantados não foram submetidos a uma validação. Também não foram definas metas para cada um dos indicadores diante da necessidade de se conhecer melhor a realidade da instituição, o que não foi feito, tendo em vista que o pesquisador se restringiu a uma análise documental para construir a proposta deste estudo.

\section{REFERÊNCIAS}

ARETIO, L. G. Educación a distancia hoy. Madrid.: UNED, 1994. BRUYNE, P. de. Dinâmica de pesquisa em ciências sociais Rio de Janeiro: Francisco Alves, 1977.

CAMPOS, J. Cenário balanceado: painel de indicadores para a gestão estratégica dos negócios. São Paulo: Aquariana, 1998.

FERNANDES, S. K. Construção do núcleo de educação a distância do SENAI/CTAI: estudo de caso. Florianópolis, 2005. 132 f. Dissertação (Mestrado) - Programa de PósGraduação em Engenharia de Produção, Universidade Federal de Santa Catarina, 2005.

FERREIRA, M. V. A. S. Planejamento estratégico: uma ferramenta efetiva para a gestão de IES. Florianópolis, 2005. 167 f. Dissertação (Mestrado) - Programa de Pós-Graduação em Administração, Universidade do Sul de Santa Catarina, 2005.

GIL, A. C. Métodos e técnicas de pesquisa social. São Paulo: Editora Atlas, 1998.

GODOY, A. S. Introdução à pesquisa qualitativa. RAE - Revista de Administração de Empresas, São Paulo, v. 35, n. 2, p. 57-63, mai.jun. 1995.

JACOBSEN, A. de L. Interação aluno-aluno em ambientes de educação convencional e a distância: um estudo de caso no programa de pós-graduação em engenharia civil da UFSC. 2004. 274 f. Tese (Doutorado) - Programa de Pós-Graduação em Engenharia de Produção, Universidade Federal de Santa Catarina, 2004.

JOHNSEN, A. Balanced scorecard: theoretical perspectives and public management implications, Managerial Auditing Journal. v. 16, n. 6, p. 319-330. 2001.

KAPLAN, R. S.; NORTON, D. P. A estratégia em ação: balanced scorecard. Rio de Janeiro: Campus, 1997.

KAPLAN, R. S.; NORTON, D. P. Organização orientada para a estratégia. Rio de Janeiro: Campus, 2001.

KEEGAN, D. Foundations of distance education. 3. ed. London: Routledge, 1996.

LANDIM, C. Educação a distância: algumas considerações. Rio de Janeiro, 1997. 
LITWIN, E. Educação a distância: temas para o debate de uma nova agenda educativa. Porto Alegre: Artmde, 2001.

MAHOLLAND, L.; MUETZ, P. A balanced scorecard approach to performance measurament. Government Finance Review, St. Charles: Illinois, p. 12-15, april. 2002.

MARTINS, O. B. A educação a distância e a democratização do saber. Petrópolis (RJ): Vozes, 1991.

MASON, R. Institutional models for virtual universities. In: TSCHANG, F. T.; DELLA SENTA, T. Access to knowledge: new Information technologies and the emergence of the virtual university. Amsterdam: UNU/IAS/ Pergamon Press, 2001.

MOORE, M. G.; KEARSLEY, G. Distance education: a systems view. Belmont (USA): Wadsworth Publishing Company, 1996.

MULLER, J. R. Desenvolvimento de modelo de gestão aplicado à universidade, tendo por base o balanced scorecard. Florianópolis. 2001. 131 f. Dissertação (Mestrado) - Programa de Pós-Graduação em Engenharia de Produção, Universidade Federal de Santa Catarina, Florianópolis, 2001.

NIVEN, P. R. Balanced scorecard passo-a-passo: elevando o desempenho e mantendo resultados.Qualitymark: Rio de Janeiro, 2005.

NUNES, I. B. Educação a distância e o mundo do trabalho. Tecnologia Educacional. Rio de Janeiro, v. 21, n. 179, p. 73-78, jul./ ago. 1995.

OLVE, N. G.; ROY, J.; WETTER, M. Condutores da performance: um guia prático para o uso do balanced scorecard. Rio de Janeiro: Qualitymark, 2001.

PESSOA, M. N. M. Gestão das Universidades Federais Brasileiras: um modelo fundamentado no balanced scorecard. Florianópolis, 2000. 291 f. Tese (Doutorado) Programa de Pós-Graduação em Engenharia de Produção, Universidade Federal de Santa Catarina, 2000.

PRETI, O. Educação a distância: uma prática educativa mediadora e mediatizada. In: Educação a distância: inícios e indícios de um percurso. Cuiabá: NEAD/IE - UFMT, p. 1556, 1996.

RAMOS, A. R.; SIMÕES, M. M.; RAMOS, M. L. G Educação à Distância e o desenvolvimento de recursos humanos. Tecnologia Educacional. Rio de Janeiro, v.18, n. 89/90/91, p. 39-48, jul./dez. 1989.

SARAIVA, T. Educação a distância no Brasil: lições da história. Em aberto, Brasília, DF, ano 16, n. 70, p. 28-33. abr/jun. 1996.

UNISUL VIRTUAL. Orientações básicas para o professor tutor. 2. ed. Tubarão: Ed. Unisul, 2004a.

VERGARA, S. H. Projetos e relatórios de pesquisa em administração. São Paulo: Atlas, 1997. 